\title{
CIGARETTE SMOKING AND MAMMOGRAPHIC BREAST DENSITY AMONG POLISH WOMEN
}

\author{
BEATA PEPŁOŃSKA and PAWEŁ KAŁUŻNY
}

\author{
Nofer Institute of Occupational Medicine, Łódź, Poland \\ Department of Environmental Epidemiology, Epidemiology Unit
}

\begin{abstract}
Objectives: High mammographic breast density (MBD) is one of the strongest breast cancer risk factors. The results of some epidemiological studies suggest that one of the lifestyle factors likely altering breast density is cigarette smoking. The aim of this study was to assess the association between active smoking, considering in detail the duration and intensity of smoking, and MBD among Polish women. Material and Methods: A cross-sectional study included 467 women aged 40-60 years who underwent screening mammography in Łódź, Poland. Volumetric mammographic density, fibroglandular tissue volume and non-fibroglandular tissue volume were determined based on the analysis of mammographic image (in the "for processing" format) using Volpara Imaging Software. Current and lifetime intensity of cigarette smoking was assessed based on the data from interviews. Linear and logistic regressions were fitted with estimated MBD parameters as the outcomes, and life-long smoking duration and intensity as the determinants, adjusted for major confounders. Results: The former smokers had a significantly lower volumetric mammographic density compared to the non-smokers in the crude analysis $(\mathrm{p}=0.022)$. However, the associations became insignificant after adjustments for important confounding factors. The analyses adjusted for important confounders revealed an inverse statistically significant association between the number of pack-years and volumetric mammographic density among the current smokers $(\mathrm{p}=0.048)$. Conclusions: The observed result is consistent with the majority of previous studies that analyzed the associations between mammographic density and life-long smoking duration. Int J Occup Med Environ Health. 2021;34(6):805-15
\end{abstract}

Key words:

breast cancer, tobacco, lifestyle, cigarette smoking, Polish women, mammographic density

\section{INTRODUCTION}

High mammographic breast density (MBD) is one of the strongest breast cancer risk factors [1]. Women with high mammographic density have a 4-fold to 6-fold increase in breast cancer risk compared with those with low breast density [2]. Mammographic breast density refers to the proportion of fibroglandular tissue (the dense area) to fatty tissue (the non-dense area) in the breast as seen on the mammogram. According to current knowledge, age and some genetic, anthropometric, reproductive or lifestyle factors are the most important determinants of MBD [3-5].

The results of some epidemiological studies suggest that one of the lifestyle factors likely altering breast density is cigarette smoking. It has been demonstrated that cigarette smoke components access breast tissues and may initi-

Funding: this study was supported by the National Science Centre in Poland (grant No. UMO-2015/17/B/NZ7/02928 entitled "Investigating causes of breast cancer a correlation between environmental cadmium exposure and mammographic density," principal investigator: Prof. Beata Pepłońska) and by the statute activity of the Nofer Institute of Occupational Medicine in Łódź (project No. IMP 10.16 entitled "Environmental determinants of mammographic density - a pilot study," principal investigator: Prof. Beata Pepłońska).

Received: February 11, 2021. Accepted: June 24, 2021.

Corresponding author: Beata Pepłońska, Nofer Institute of Occupational Medicine, Department of Environmental Epidemiology, Epidemiology Unit, św. Teresy 8 , 91-348 Łódź, Poland (e-mail: beata.peplonska@imp.lodz.pl). 
ate cells proliferation [6-8]. In contrast to the stimulating proliferation properties of cigarette smoke components, some data also suggest anti-estrogenic effects of smoking $[9,10]$.

It has also been hypothesized that the alteration of breast architecture and composition may result from an increased intensity of the ageing process among smokers, probably via elevation of oxidative stress. It is known that the oxidative stress among smokers derives from an excessive increase in free radicals as well as a reduction in enzymatic and non-enzymatic antioxidant mechanisms [11]. The epidemiological evidence on the association between the smoking status and breast density has been limited and inconsistent so far. Of the 15 epidemiological studies, most have evaluated the relationship with the current smoking status and found a lower mammographic density among current smokers when compared to former smokers or non-smokers [12-22]. The association between the lifelong smoking duration or intensity and breast density has been rarely addressed [4,12-15].

Thus, the aim of this study was to further explore the association between active smoking and MBD, considering in detail the duration and intensity of smoking, among Polish women using a fully automated, quantitative measure of MBD.

\section{MATERIAL AND METHODS}

\section{Study design and population}

The study population was described earlier [23]. Briefly, a cross-sectional study of MBD was carried out in the city of Łódź, Poland, in 2013-2018. The participating women were recruited at 2 mammographic screening centers to which they reported voluntarily to undergo mammography. The inclusion criteria were as follows: 40-60 years of age, residing in Łódź, no previous diagnosis of breast cancer, no history of breast augmentation surgery/implants, and no hormone replacement therapy (HRT) declared at the time of recruitment. Considering that women aged 50-69 years are eligible to attend the national mammography screening, which is funded from government sources every 2 years, this sampling frame was populationbased. Programs for women aged 40-49 years are also in place, but they are carried out on a minor scale and on a more irregular basis.

Overall, 600 women were initially classified as eligible for the study inclusion and provided their consent for participation. However, 133 of these women were then excluded - 43 due to subsequent refusals, 58 due to not providing data on a history of cigarette smoking, and 6 due to the fact that, when interviewed, they reported using HRT. Furthermore, the mammographic images of 26 women had not been recorded in the raw "for processing" format which is needed for volumetric density calculations to be performed. Eventually, the analysis covered data of 467 women.

\section{Ethics statement}

The study was approved by the Bioethics Committee at the Nofer Institute of Occupational Medicine (NIOM) (approval No. 2/2012 of March 13, 2012, and approval No. 3/2016 of April 1, 2016). A signed informed consent form was obtained from each study participant.

\section{Questionnaire and anthropometric measurements}

Personal interviews were carried out (on average within 1.5 month since the mammographic examination) to obtain data on a history of cigarette smoking, demographic data, menstruation and menopause data, the reproductive history, a history of contraceptive medications usage, menopausal hormone therapy and lifestyle factors.

Trained nurses were engaged to perform anthropometric measurements (within an average of 1 month after the mammographic examination), including the body weight and height, and the hip and waist circumferences. The body mass index (BMI) (the body weight divided by the squared height, expressed in $\mathrm{kg} / \mathrm{m}^{2}$ ), as well as 
the waist-to-hip ratio (i.e., the umbilical waist circumference expressed in $\mathrm{cm}$, divided by the hip circumference) were also calculated.

\section{Smoking assessment}

The women were interviewed both about their current smoking status and lifetime smoking history. The women who reported having never smoked were categorized as non-smokers (the reference group). The women who during the interview reported having ever been active smokers were categorized according to their current smoking status, either as current smokers or as former smokers.

Based on the collected data, pack-years were calculated for both the current and former smokers. The participants of the study were asked to provide retrospective information on the average number of cigarettes per day which they smoked during each of the following 4 decades of their life: 20-29, 30-39, 40-49, and 50-59 years of age. To determine the pack-years smoked, the reported number of cigarettes smoked per day during each decade was multiplied by active smoking duration (in years) and divided by 20 (the standard number of cigarettes in a pack). If a woman reported that she had quitted smoking during one of the decades, the active smoking duration was shortened up to the cessation year. Among the current smokers, the active smoking duration during the last decade of their life was calculated up to the age of the study participants at the time of the interview. The total number of pack-years corresponded to the sum of pack-years smoked in each decade.

The former smokers were categorized according to the time since smoking cessation (ranges: $\geq 1-10 ;>10-20$; $>20$ years) and to the number of pack-years smoked (ranges: $\geq 0.15-10 ;>10-20 ;>20-85$ ). The current smokers were categorized according to the number of packyears smoked (ranges: $\geq 0.15-10 ;>10-20$; $>20-85$ ), and to the number of cigarettes smoked per day (ranges: $\geq 1-7$; >7-15; >15-50). Moreover, the women who reported having ever been active smokers were categorized into 2 groups according to their age at smoking initiation $(<20$ years or $>20$ years).

\section{Mammography and mammographic density assessment} Two mammographic screening centers were engaged to perform digital mammography. The first center used Mammomat Novation DR, Mammomat Fusion (Siemens Healthcare GmbH, Erlangen, Germany) while Lorad Selenia, Selenia Dimensions (Hologic Inc., Malvern, USA) was used in the second one, in both cases according to standard procedures. Breast examinations were performed in craniocaudal and mediolateral projections. Volpara Imaging Software (Volpara Health Technologies Ltd., Wellington, New Zealand), algorithm v. 1.5.5.1, was used to analyze the raw data (in the "for processing" format) generated by the digital mammography system. Volpara applies a physics-based model whose principles were earlier described by Highnam et al. [24] as an extension of the method proposed by van Engeland et al. [25].

Briefly speaking, the algorithm is used to determine the $\mathrm{X}$-ray attenuation between the image detector and the X-ray source based on the image pixel signal. The pixel intensity corresponding to purely adipose tissue provides a point of reference for all other pixels in calculating the thickness of fibroglandular tissue which must be present to contribute to the X-ray attenuation being relatively greater than at the fatty point of reference. The volumes of adipose tissue and fibroglandular tissue are summarized across the whole breast. The volumetric breast density (VBD), expressed as a percentage, is calculated as the ratio of the fibroglandular tissue volume to the total breast volume.

\section{Statistical analysis}

To characterize the study population by the current smoking status, arithmetic means (for continuous variables) 
and frequencies (for categorical variables) were calculated in each subgroup. Student's t-test was used to compare the means of the continuous variables, while the $\chi^{2}$ test was employed to compare the distribution of the categorical variables in the study population.

The means and standard deviations for the estimates of fibroglandular tissue volume $\left(\mathrm{cm}^{3}\right)$, non-fibroglandular tissue volume $\left(\mathrm{cm}^{3}\right)$ and volumetric mammographic density (\%) for the left and right breasts, and their average, were also established.

The following variables were viewed as potential confounders of cigarette smoking and MBD associations based on the literature review: age at mammography (continuous), BMI (continuous), the menopausal status (prevs. post-menopausal), age at menarche (continuous), age at menopause among the post-menopausal women (continuous), a history of hormonal contraceptives usage (ever vs. never), parity (ever vs. never), breastfeeding (ever vs. never), and a family history of breast cancer (yes vs. no).

The women who reported having their last menstrual bleeding within the past 365 days were classified as premenopausal; otherwise, they were assigned a post-menopausal status. The variables depicting the possible variability due to the applied technique of mammographic data collection, i.e., the mammographic screening center (1 vs. 2), the mammographic X-ray system (Siemens vs. Hologic) and the mammographic device (apparatus) (Mammomat Novation DR, Mammomat Fusion, vs. Lorad Selenia, Selenia Dimensions), were additionally analyzed.

All of the potential confounding factors listed above were tested in the multivariate model to assess their associations with VBD as the outcome variable. A stepwise variable selection with Akaike information criterion was applied, with age at mammography, BMI, the menopausal status, age at menarche, a family history of breast cancer, and the mammographic device being retained in the final model.
Linear regression models (crude and mutually adjusted) were applied to calculate the association between age, BMI and reproductive factors, as well as estimated MBD parameters.

The results regarding the association between the current smoking status and volumetric mammographic density, fibroglandular tissue volume and non-fibroglandular tissue volume, which were considered as dependent variables in the model, are presented as estimated marginal means with standard errors $\mathrm{M}(\mathrm{SE})$. Dunnett's test (analogous to the t-test adjusted for 2 comparisons with a single control group) was used to compare the crude and adjusted marginal means of MBD parameters among both the current smokers and the former smokers, with the means being estimated for the non-smokers.

In the analysis of life-long smoking duration and intensity, 5 independent categorical variables were included: the time since smoking cessation among the former smokers, the number of pack-years smoked both among the former and current smokers, the number of cigarettes smoked per day among the current smokers, and age at smoking initiation. The results regarding volumetric mammographic density, fibroglandular tissue volume and non-fibroglandular tissue volume, which were analyzed as dependent variables in the model, are presented as $\mathrm{M}_{\text {adj }}(\mathrm{SE})$ and p-values for trends. Moreover, linear regression models were applied to calculate the association between life-long smoking duration and smoking intensity, expressed as continuous variables and estimated MBD parameters. The results are presented as $\beta$-coefficients and $p$-values for trends.

The R software (R Core Team, 2018) v. 3.5.2 was used for statistical analyses.

\section{RESULTS}

The characteristics of the study population stratified by the current smoking status are presented in Table 1 . A higher prevalence of pre-menopausal women was observed among the non-smokers than among the current 
Table 1. Selected characteristics of women, aged 40-60 years, undergoing screening mammography in 2013-2018 in 2 screening centers in Łódź, Poland

\begin{tabular}{|c|c|c|c|c|}
\hline \multirow{2}{*}{ Variable } & \multicolumn{3}{|c|}{$\begin{array}{l}\text { Participants' smoking status } \\
\qquad(\mathrm{N}=467)\end{array}$} & \multirow{2}{*}{$\mathrm{p}$} \\
\hline & $\begin{array}{l}\text { non-smoker } \\
(\mathrm{N}=228)\end{array}$ & $\begin{array}{l}\text { former smoker } \\
\qquad(\mathrm{N}=145)\end{array}$ & $\begin{array}{l}\text { current smoker } \\
\quad(\mathrm{N}=94)\end{array}$ & \\
\hline \multicolumn{5}{|l|}{ Age [years] $(\mathrm{M} \pm \mathrm{SD})$} \\
\hline at mammography & $53.93 \pm 3.94$ & $55.05 \pm 3.60$ & $53.86 \pm 3.67$ & 0.011 \\
\hline at menarche & $13.33 \pm 1.58$ & $13.33 \pm 1.39$ & $13.31 \pm 1.45$ & 0.994 \\
\hline at menopause & $50.32 \pm 4.05$ & $49.92 \pm 3.69$ & $49.52 \pm 3.25$ & 0.285 \\
\hline $\mathrm{BMI}\left[\mathrm{kg} / \mathrm{m}^{2}\right](\mathrm{M} \pm \mathrm{SD})$ & $26.64 \pm 4.57$ & $28.01 \pm 4.55$ & $27.50 \pm 5.13$ & 0.020 \\
\hline Menopausal status [n (\%)] & & & & 0.022 \\
\hline pre-menopausal & $60(26.3)$ & $23(15.9)$ & $15(16.0)$ & \\
\hline post-menopausal & $168(73.7)$ & $122(84.1)$ & $79(84.0)$ & \\
\hline Parity $[\mathrm{n}(\%)]$ & & & & 0.063 \\
\hline yes & $208(91.2)$ & $141(97.2)$ & $86(91.5)$ & \\
\hline no & $20(8.8)$ & $4(2.8)$ & $8(8.5)$ & \\
\hline Ever breastfeeding [n (\%)] & & & & 0.545 \\
\hline yes & $156(68.4)$ & $92(63.4)$ & $60(63.8)$ & \\
\hline no & $72(31.6)$ & $53(36.6)$ & $34(36.2)$ & \\
\hline Ever using oral contraceptives [n $(\%)]$ & & & & 0.962 \\
\hline yes & $69(30.3)$ & $43(29.7)$ & $27(28.7)$ & \\
\hline no & $159(69.7)$ & $102(70.3)$ & $67(71.3)$ & \\
\hline Family history of breast cancer [n (\%)] & & & & 0.746 \\
\hline yes & $29(12.7)$ & $15(10.3)$ & $10(10.6)$ & \\
\hline no & $199(87.3)$ & $130(89.7)$ & $84(89.4)$ & \\
\hline Mammographic device [n (\%)] & & & & 0.095 \\
\hline Mammomat Novation $^{\text {DR }}$ & $54(23.7)$ & $36(24.8)$ & $21(22.3)$ & \\
\hline Mammomat Fusion & $44(19.3)$ & $22(15.2)$ & $23(24.5)$ & \\
\hline Lorad Selenia & $56(24.6)$ & $51(35.2)$ & $31(33.0)$ & \\
\hline Selenia Dimensions & $74(32.4)$ & $36(24.8)$ & $19(20.2)$ & \\
\hline
\end{tabular}

or former smokers $(p=0.022)$. Differences between the compared groups were also found for BMI and age at mammography. The non-smokers had significantly lower BMI and were younger at mammography than the former smokers. Other characteristics were similarly distributed across the compared groups of women.
The results of the multivariable regression analysis for age, BMI, and reproductive factors are presented in Table 2. In the study population, volumetric mammographic density was positively associated with age at menarche, and inversely associated with age and BMI. Moreover, an inverse relationship was found between age and fibroglandular tissue volume. 
Table 2. The association between selected factors and percent volumetric mammographic density and tissue volume among women ( $\mathrm{N}=467$ ), aged 40-60 years, undergoing screening mammography in 2013-2018 in 2 screening centers in Łódź, Poland results of a multivariable linear regression analysis

\begin{tabular}{|c|c|c|c|c|c|c|c|c|c|}
\hline \multirow{3}{*}{ Factor } & \multirow{2}{*}{\multicolumn{3}{|c|}{$\begin{array}{l}\text { Percent volumetric } \\
\text { mammographic density }\end{array}$}} & \multicolumn{6}{|c|}{ Tissue volume } \\
\hline & & & & \multicolumn{3}{|c|}{ fibroglandular } & \multicolumn{3}{|c|}{ non-fibroglandular } \\
\hline & $\beta^{\mathrm{a}}$ & SE & $\mathrm{p}$ & $\beta$ & SE & $\mathrm{p}$ & $\beta$ & SE & $\mathrm{p}$ \\
\hline Age [years] & -0.2199 & 0.06 & $<0.001$ & -1.006 & 0.46 & 0.030 & 3.6 & 5.2 & 0.48 \\
\hline $\mathrm{BMI}\left[\mathrm{kg} / \mathrm{m}^{2}\right]$ & -0.4425 & 0.04 & $<0.001$ & 1.322 & 0.30 & $<0.001$ & 68.0 & 3.4 & $<0.001$ \\
\hline Menopausal status (post- vs. pre-menopausal) & -0.1188 & 0.56 & 0.832 & -9.920 & 4.26 & 0.020 & -34.8 & 47.8 & 0.47 \\
\hline Age at menarche [years] & 0.2695 & 0.13 & 0.032 & 1.691 & 0.95 & 0.076 & -4.4 & 10.7 & 0.68 \\
\hline Parity (yes vs. no) & 0.0052 & 0.80 & 0.995 & 2.644 & 6.07 & 0.664 & -13.7 & 68.2 & 0.84 \\
\hline Ever breastfeeding (yes vs. no) & -0.2277 & 0.43 & 0.598 & 2.069 & 3.27 & 0.528 & 36.1 & 36.8 & 0.33 \\
\hline Ever using oral contraceptives (yes vs. no) & 0.0990 & 0.41 & 0.809 & 0.074 & 3.11 & 0.981 & -8.8 & 34.9 & 0.80 \\
\hline Family history of breast cancer (yes vs. no) & 1.0955 & 0.58 & 0.058 & 12.238 & 4.38 & 0.006 & -53.3 & 49.2 & 0.28 \\
\hline
\end{tabular}

${ }^{a}$ Mutually adjusted.

Table 3. Estimated marginal means of percent volumetric mammographic density and tissue volume by current smoking status among women ( $\mathrm{N}=467)$, aged 40-60 years, undergoing screening mammography in 2013-2018 in 2 screening centers in Łódź, Poland

\begin{tabular}{|c|c|c|c|c|c|c|}
\hline \multirow{3}{*}{ Smoking status } & \multirow{2}{*}{\multicolumn{2}{|c|}{$\begin{array}{l}\text { Percent volumetric } \\
\text { mammographic density }\end{array}$}} & \multicolumn{4}{|c|}{ Tissue volume $\left(\mathrm{cm}^{3}\right)$} \\
\hline & & & \multicolumn{2}{|c|}{ fibroglandular } & \multicolumn{2}{|c|}{ non-fibroglandular } \\
\hline & crude $\mathrm{M}(\mathrm{SE})$ & $\operatorname{adjusted}^{\mathrm{c}} \mathrm{M}(\mathrm{SE})$ & crude $\mathrm{M}(\mathrm{SE})$ & adjusted $^{\mathrm{c}} \mathrm{M}(\mathrm{SE})$ & crude $\mathrm{M}(\mathrm{SE})$ & adjusted $^{\mathrm{c}} \mathrm{M}(\mathrm{SE})$ \\
\hline Current smokers $(\mathrm{N}=94)$ & $7.64(0.47)$ & $7.57(0.41)$ & $61.25(3.25)$ & $60.93(3.13)$ & $914.19(47.42)$ & $903.82(35.12)$ \\
\hline Former smokers $(\mathrm{N}=145)$ & $7.19(0.38)$ & $7.69(0.33)$ & $60.18(2.62)$ & $60.77(2.54)$ & $897.06(38.18)$ & $849.96(28.48)$ \\
\hline Non-smokers $(\mathrm{N}=228)$ & $8.41(0.30)$ & $8.03(0.27)$ & $62.62(2.09)$ & $62.46(2.04)$ & $822.27(30.45)$ & $865.57(22.85)$ \\
\hline $\mathrm{p}^{\mathrm{a}}$ & 0.294 & 0.541 & 0.899 & 0.872 & 0.186 & 0.562 \\
\hline $\mathrm{p}^{\mathrm{b}}$ & 0.022 & 0.635 & 0.681 & 0.815 & 0.224 & 0.865 \\
\hline
\end{tabular}

${ }^{a}$ Current smokers vs. non-smokers.

${ }^{\mathrm{b}}$ Former smokers vs. non-smokers.

${ }^{\mathrm{c}}$ Adjusted for: age at mammography, BMI, menopausal status, age at menarche, family history of breast cancer, mammographic device.

Fibroglandular tissue volume was also positively associated with BMI. The post-menopausal women had a lower fibroglandular tissue volume than the pre-menopausal women. Interestingly, the women who reported a family history of breast cancer had higher fibroglandular tissue volume than the women with no such history. Non-fibroglandular tissue volume (fat tissue) was associated with BMI.

The crude and adjusted means of volumetric mammographic density, fibroglandular tissue volume and non-fi- broglandular tissue volume by the current smoking status are presented in Table 3. Both the current and former smokers had a lower volumetric mammographic density ( $7.6 \%$ and $7.2 \%$, respectively) compared to the non-smokers $(8.4 \%)$ in the crude analysis. However, the associations became insignificant after adjustments for important confounding factors. No associations were noted between the current smoking status and both fibroglandular tissue volume and non-fibroglandular tissue volume. 
Table 4. Adjusted mean percent volumetric mammographic density, fibroglandular tissue volume and non-fibroglandular tissue volume by life-long smoking exposure among women ( $\mathrm{N}=467)$, aged 40-60 years, undergoing screening mammography in 2013-2018 in 2 screening centers in Łódź, Poland

\begin{tabular}{|c|c|c|c|c|c|c|c|}
\hline \multirow[t]{2}{*}{ Smoking exposure } & \multirow[t]{2}{*}{$\begin{array}{l}\text { Participants } \\
\text { [n] }\end{array}$} & \multirow{2}{*}{$\begin{array}{l}\text { Percent volumetric } \\
\text { mammographic } \\
\text { density } \\
(\mathrm{M}(\mathrm{SE}))^{\mathrm{a}}\end{array}$} & \multirow[t]{2}{*}{$\mathrm{p}$} & \multicolumn{4}{|c|}{$\begin{array}{c}\text { Tissue volume } \\
\left.\qquad \mathrm{cm}^{3}\right] \\
(\mathrm{M}(\mathrm{SE}))\end{array}$} \\
\hline & & & & fibroglandular ${ }^{\mathrm{a}}$ & $\mathrm{p}$ & non-fibroglandular ${ }^{\mathrm{a}}$ & $\mathrm{p}$ \\
\hline $\begin{array}{l}\text { Cigarettes smoked per day } \\
\text { among current smokers }\end{array}$ & & & $0.081^{\#}$ & & $0.476^{\#}$ & & $0.806^{\#}$ \\
\hline $1-7$ & 25 & $9.45(0.80)$ & & $67.18(6.74)$ & & $852.36(60.93)$ & \\
\hline$>7-15$ & 36 & $7.37(0.67)$ & & $63.93(5.67)$ & & $990.04(51.25)$ & \\
\hline$>15-50$ & 28 & $6.39(0.76)$ & & $55.25(6.46)$ & & $899.63(58.34)$ & \\
\hline $\begin{array}{l}\text { Pack-years smoked among } \\
\text { current smokers }{ }^{\mathrm{c}}\end{array}$ & & & $0.048^{\#}$ & & $0.576^{\#}$ & & $0.364^{\#}$ \\
\hline $0.15-10$ & 20 & $8.93(0.89)$ & & $64.37(7.47)$ & & $874.05(68.06)$ & \\
\hline$>10-20$ & 35 & $8.22(0.67)$ & & $64.63(5.65)$ & & $910.86(51.44)$ & \\
\hline$>20-85$ & 38 & $6.11(0.64)$ & & $56.15(5.36)$ & & $954.66(48.83)$ & \\
\hline $\begin{array}{l}\text { Pack-years smoked among } \\
\text { former smokers }{ }^{\mathrm{d}}\end{array}$ & & & $0.431^{\#}$ & & $0.981^{\#}$ & & $0.228^{\#}$ \\
\hline $0.15-10$ & 83 & $7.28(0.41)$ & & $59.65(3.31)$ & & $865.12(40.62)$ & \\
\hline$>10-20$ & 31 & $7.26(0.69)$ & & $64.19(5.52)$ & & $975.88(67.81)$ & \\
\hline$>20-85$ & 21 & $6.74(0.83)$ & & $56.60(6.67)$ & & $927.14(82.03)$ & \\
\hline Age at smoking initiation ${ }^{\mathrm{e}}$ & & & 0.584 & & 0.354 & & 0.431 \\
\hline$<20$ years & 125 & $7.46(0.34)$ & & $58.86(2.86)$ & & $890.48(29.89)$ & \\
\hline$>20$ years & 112 & $7.19(0.36)$ & & $62.75(3.02)$ & & $925.13(31.61)$ & \\
\hline $\begin{array}{l}\text { Time since smoking cessation } \\
\text { among former smokers }\end{array}$ & & & $0.293^{\#}$ & & $0.866^{\#}$ & & $0.343^{\#}$ \\
\hline $1-10$ years & 40 & $6.64(0.59)$ & & $64.35(5.18)$ & & $971.16(58.99)$ & \\
\hline$>10-20$ years & 49 & $7.68(0.52)$ & & $61.81(4.61)$ & & $901.72(52.50)$ & \\
\hline$>20-38$ years & 40 & $7.24(0.59)$ & & $57.92(5.15)$ & & $857.64(58.63)$ & \\
\hline
\end{tabular}

a Adjusted for: age at mammography, BMI, menopausal status, age at menarche, family history of breast cancer, mammographic device.

${ }^{\mathrm{b}}$ Missing information on the number of cigarettes currently smoked per day for 5 women.

${ }^{\mathrm{c}}$ Missing information on pack-years calculation across lifespan for 1 woman.

${ }^{\mathrm{d}}$ Missing information on pack-years calculation across lifespan for 10 woman.

${ }^{\mathrm{e}}$ Missing information on age at smoking initiation for 2 women.

${ }^{\mathrm{f}}$ Missing information on the year of smoking cessation for 16 women.

\# p-trend.

Table 4 displays the results regarding the association between life-long smoking duration and the MBD parameters under analysis. Among the current smokers, the number of pack-years was associated with a decreased volumetric mammographic density. No significant associations were noted between other life-long smoking duration variables and estimated MBD parameters. Both volumetric mammographic density and fibroglandular tissue 
Table 5. Linear regression analysis of the association between life-long smoking duration and intensity variables, and estimated breast mammographic density parameters, among women $(\mathrm{N}=467)$, aged $40-60$ years, undergoing screening mammography in 2013-2018 in 2 screening centers in Łódź, Poland

\begin{tabular}{|c|c|c|c|c|c|c|c|c|c|}
\hline \multirow{3}{*}{ Smoking exposure } & \multirow{2}{*}{\multicolumn{3}{|c|}{$\begin{array}{l}\text { Percent volumetric } \\
\text { mammographic density }\end{array}$}} & \multicolumn{6}{|c|}{ Tissue volume } \\
\hline & & & & \multicolumn{3}{|c|}{ fibroglandular } & \multicolumn{3}{|c|}{ non-fibroglandular } \\
\hline & $\beta$ & SE & $\mathrm{p}$ & $\beta$ & SE & $\mathrm{p}$ & $\beta$ & SE & $\mathrm{p}$ \\
\hline $\begin{array}{l}\text { Cigarettes smoked per day } \\
\text { among current smokers }\end{array}$ & -0.093 & 0.05 & 0.081 & -0.308 & 0.43 & 0.476 & 0.967 & 3.92 & 0.806 \\
\hline Pack-years smoked among current smokers & -0.069 & 0.03 & 0.048 & -0.159 & 0.28 & 0.576 & 2.332 & 2.56 & 0.364 \\
\hline Pack-years smoked among former smokers & -0.025 & 0.03 & 0.431 & 0.007 & 0.27 & 0.981 & 3.797 & 3.14 & 0.228 \\
\hline $\begin{array}{l}\text { Time since smoking cessation } \\
\text { among former smokers in years }\end{array}$ & 0.035 & 0.03 & 0.293 & -0.05 & 0.29 & 0.866 & -3.216 & 3.38 & 0.343 \\
\hline
\end{tabular}

volume tended to be lower with the increased intensity of cigarette smoking. A certain increase in non-fibroglandular tissue volume with the number of pack-years among the current smokers was also observed.

The results of the linear regression analysis of the associations between life-long smoking duration and intensity variables, expressed as continuous variables, and estimated MBD parameters are presented in Table 5. The estimates were consistent with the data presented in Table 4.

\section{DISCUSSION}

The present cross-sectional study investigated the associations between cigarette smoking and MBD parameters among 467 women. The analyses adjusted for important confounders revealed an inverse association between the number of pack-years and volumetric mammographic density among the current smokers. This result is consistent with the majority of previous studies that analyzed the associations between mammographic density and either the current smoking status or life-long smoking duration.

A significantly lower breast density among current smokers than among former smokers or non-smokers was reported in 10 [12,13,15-22] out of 15 studies [4,12-22,26-28]. Furthermore, the relationship between the life-long smoking duration or intensity and breast density was also recorded. These relationships were consistently observed in both pre- and post-menopausal women, in younger and older women, and in various ethnic backgrounds [12-15].

Some studies have also indicated that the early smoking initiation $[13,15]$ and smoking duration in years, irrespective of smoking intensity [13], are important determinants of breast density. Years since smoking cessation were generally not predictive of mammographic density, as was also observed in this study.

The biological plausibility of the inverse association between smoking and breast density has been explained mostly by the anti-estrogenic effect of smoking. It has been documented that tobacco smoke accelerates the metabolism of estradiol to biologically inactive metabolites, increases the binding of estrogens by serum sex hormone-binding globulin, as well as inhibits the formation of estrogens during the aromatization process of androgens into estrogens, eventually leading to a lower circulating level of estrogens and potentially to a decreased MBD [9,13]. While cigarette smoke contains some amounts of cadmium, which has been shown to exert estrogenic-like activity [29], an inverse relation with cadmium was observed, in the population studied especially among the post-menopausal women [23]. Inverse 
relations with airborne cadmium have been also observed among post-menopausal women in the Breast Cancer Consortium Surveilance study [30]. Of concern is that cadmium has shown a positive association with particulate matter present in outdoor air pollution, even after adjustment for smoking [31].

This study has several strong points. It was conducted in a relatively well described population of women. Personal interviews allowed for collecting personal data about the study participants according to a standardized questionnaire. Detailed information was collected and analyzed about smoking habits including lifetime smoking data and pack-years calculations. The major confounders were evaluated and adjusted in the analysis. Mammographic features were evaluated fully automatically and objectively. The superiority of the volumetric method lies in the fact that it takes into account breast thickness, and is expected to better reflect the amount of the fibroglandular tissue in the breast than the planar methods. The eligible study population was restricted to those participants who were not using HRT to avoid a strong confounding effect. Furthermore, the analysis confirmed some wellestablished correlations of such factors as age, BMI and the menopausal status with estimated MBD parameters, which supports the validity of the study.

However, the authors also acknowledge that the study may exhibit some limitations. Typically for questionnaire-based studies some recall bias may have been present, which could also affect data about a history of cigarette smoking. This imprecision might cause some distortion of the results towards the null, given that the misclassification that may have occurred was likely non-differential in respect to MBD. The population under analysis was not randomly selected from the general population; therefore, the study group characteristics may not reflect those in the general population of women in Łódź or in Poland.

Finally, the study population was relatively small; however, the method of breast density examination was pre- sumably more precise than the semiautomatic or quantitative methods used in previous studies, and the power calculations that were performed indicated that the study had the sufficient power of $80 \%$ to detect a difference of $1.6 \%$ in MBD.

\section{CONCLUSIONS}

To sum up, this study revealed a weak inverse association between the number of pack-years and volumetric mammographic density among the current smokers. This observation is consistent with the majority of previous studies conducted in this area of research.

\section{REFERENCES}

1. Boyd NF, Martin LJ, Bronskill M, Yaffe MJ, Duric N, Minkin S. Breast tissue composition and susceptibility to breast cancer. J Natl Cancer Inst. 2010;102(16):1224-37, https://doi. org/10.1093/jnci/djq239.

2. McCormack VA, dos Santos Silva I. Breast density and parenchymal patterns as markers of breast cancer risk: a meta-analysis. Cancer Epidemiol Biomarkers Prev. 2006;15(6):1159-69, https://doi.org/10.1158/1055-9965.EPI-06-0034.

3. Sherratt MJ, McConnell JC, Streuli CH. Raised mammographic density: causative mechanisms and biological consequences. Breast Cancer Res. 2016;18(1):45, https://doi.org/ 10.1186/s13058-016-0701-9.

4. Brand JS, Czene K, Eriksson L, Trinh T, Bhoo-Pathy N, Hall P, et al. Influence of Lifestyle Factors on Mammographic Density in Postmenopausal Women. Plos One. 2013;8(12), https:// doi.org/10.1371/journal.pone.0081876.

5. Alexeeff SE, Odo NU, McBride R, McGuire V, Achacoso N, Rothstein JH, et al. Reproductive Factors and Mammographic Density: Associations Among 24,840 Women and Comparison of Studies Using Digitized Film-Screen Mammography and Full-Field Digital Mammography. Am J Epidemiol. 2019; 188(6):1144-54, https://doi.org/10.1093/aje/kwz033.

6. Thompson PA, DeMarini D, Kadlubar FF, McClure GY, Brooks LR, Green BL, et al. Evidence for the presence of 
mutagenic arylamines in human breast milk and DNA adducts in exfoliated breast ductal epithelial cells. Environ Mol Mutagen. 2002;39(2-3):134-42, https://doi.org/10.1002/ em.10067.

7. Li D, Wang M, Dhingra K, Hittelman WN. Aromatic DNA adducts in adjacent tissues of breast cancer patients: clues to breast cancer etiology. Cancer Res. 1996;56(2):287-93.

8. Perera FP, Estabrook A, Hewer A, Channing K, Rundle A, Mooney LA, et al. Carcinogen-DNA Adducts in Human Breast-Tissue. Cancer Epidem Biomar. 1995;4(3):233-8.

9. Baron JA, La Vecchia C, Levi F. The antiestrogenic effect of cigarette smoking in women. Am J Obstet Gynecol. 1990;162(2):502-14, https://doi.org/10.1016/0002-9378(90) 90420-c.

10. Tanko LB, Christiansen C. An update on the antiestrogenic effect of smoking: a literature review with implications for researchers and practitioners. Menopause. 2004;11(1):104-9, https://doi.org/10.1097/01.Gme.0000079740.18541.Db.

11. Nicita-Mauro V, Basile G, Maltese G, Nicita-Mauro C, Gangemi S, Caruso C. Smoking, health and ageing. Immun Ageing. 2008;5:10, https://doi.org/10.1186/1742-4933-5-10.

12. Bremnes Y, Ursin G, Bjurstam N, Gram IT. Different measures of smoking exposure and mammographic density in postmenopausal Norwegian women: a cross-sectional study. Breast Cancer Res. 2007;9(5):R73, https://doi.org/10.1186/ bcr1782.

13. Jacobsen KK, Lynge E, Vejborg I, Tjonneland A, von Euler-Chelpin M, Andersen ZJ. Cigarette smoking and mammographic density in the Danish Diet, Cancer and Health cohort. Cancer Causes Control. 2016;27(2):271-80, https:// doi.org/10.1007/s10552-015-0704-3.

14. Cabanes A, Pastor-Barriuso R, Garcia-Lopez M, PedrazPingarron C, Sanchez-Contador C, Carrete JAV, et al. Alcohol, tobacco, and mammographic density: a populationbased study. Breast Cancer Res Tr. 2011;129(1):135-47, https://doi.org/10.1007/s10549-011-1414-5.

15. Butler LM, Gold EB, Conroy SM, Crandall CJ, Greendale GA, Oestreicher N, et al. Active, but not passive cigarette smoking was inversely associated with mammographic density. Cancer Cause Control. 2010;21(2):301-11, https://doi.org/10.1007/s10552-009-9462-4.

16. Stone J, Warren RML, Pinney E, Warwick J, Cuzick J. Determinants of Percentage and Area Measures of Mammographic Density. Am J Epidemiol. 2009;170(12):1571-8, https://doi.org/10.1093/aje/kwp313.

17. McBride RB, Fei K, Rothstein JH, Alexeeff SE, Song X, Sakoda LC, et al. Alcohol and Tobacco Use in Relation to Mammographic Density in 23,456 Women. Cancer Epidemiol Biomarkers Prev. 2020;29(5):1039-48, https://doi.org/ 10.1158/1055-9965.EPI-19-0348.

18. Modugno F, Ngo DL, Allen GO, Kuller LH, Ness RB, Vogel VG, et al. Breast cancer risk factors and mammographic breast density in women over age 70. Breast Cancer Res Tr. 2006;97(2):157-66, https://doi.org/10.1007/s10549-005-9105-8.

19. Sala E, Warren R, McCann J, Duffy S, Luben R, Day N. Smoking and high-risk mammographic parenchymal patterns: a case-control study. Breast Cancer Res. 2000;2(1): 59-63, https://doi.org/10.1186/bcr29.

20. Vachon CM, Kuni CC, Anderson K, Anderson VE, Sellers TA. Association of mammographically defined percent breast density with epidemiologic risk factors for breast cancer (United States). Cancer Cause Control. 2000;11(7): 653-62, https://doi.org/10.1023/A:1008926607428.

21. Warwick J, Pinney E, Warren RML, Duffy SW, Howell A, Wilson $\mathrm{M}$, et al. Breast density and breast cancer risk factors in a high-risk population. Breast. 2003;12(1):10-6, https:// doi.org/10.1016/S0960-9776(02)00212-6.

22. Jeffreys M, Warren R, Gunnell D, McCarron P, Smith GD. Life course breast cancer risk factors and adult breast density (United Kingdom). Cancer Causes Control. 2004;15(9): 947-55, https://doi.org/10.1007/s10522-004-2473-3.

23. Peplonska B, Janasik B, McCormack V, Bukowska-Damska A, Kaluzny P. Cadmium and volumetric mammographic density: A cross-sectional study in Polish women. PLoS One. 2020;15(5):e0233369, https://doi.org/10.1371/journal.pone. 0233369 . 
24. Highnam R, Brady SM, Yaffe MJ, Karssemeijer N, Harvey J. Robust Breast Composition Measurement - Volpara $^{\mathrm{TM}}$. In: Martí J, Oliver A, Freixenet J, Martí R, editors. Digital Mammography. Lecture Notes in Computer Science. Vol 6136. Berlin, Heidelberg: Springer; 2010.

25. Van Engeland S, Snoeren PR, Huisman H, Boetes C, Karssemeijer N. Volumetric breast density estimation from full-field digital mammograms. IEEE Trans Med Imaging. 2006;25(3):273-82, https://doi.org/10.1109/TMI.2005. 862741.

26. Gapstur SM, Lopez P, Colangelo LA, Wolfman J, Van Horn L, Hendrick RE. Associations of breast cancer risk factors with breast density in Hispanic women. Cancer Epidemiol Biomarkers Prev. 2003;12(10):1074-80.

27. Roubidoux MA, Kaur JS, Griffith KA, Stillwater B, Novotny P, Sloan J. Relationship of mammographic parenchymal patterns to breast cancer risk factors and smoking in Alaska Native women. Cancer Epidemiol Biomarkers Prev. 2003;12(10):1081-6.
28. Pereira A, Garmendia ML, Uauy R, Neira P, Lopez-Arana S, Malkov S, et al. Determinants of volumetric breast density in Chilean premenopausal women. Breast Cancer Res Treat. 2017;162(2):343-52, https://doi.org/10.1007/ s10549-017-4126-7.

29. Johnson MD, Kenney N, Stoica A, Hilakivi-Clarke L, Singh B, Chepko G, et al. Cadmium mimics the in vivo effects of estrogen in the uterus and mammary gland. Nat Med. 2003;9(8):1081-4, https://doi.org/10.1038/nm902.

30. White AJ, Weinberg CR, O'Meara ES, Sandler DP, Sprague BL. Airborne metals and polycyclic aromatic hydrocarbons in relation to mammographic breast density. Breast Cancer Res. 2019;21(1):24, https://doi.org/10.1186/s13058019-1110-7.

31. Filippini T, Michalke B, Malagoli C, Grill P, Bottecchi I, Malavolti M, et al. Determinants of serum cadmium levels in a Northern Italy community: A cross-sectional study. Environ Res. 2016;150:219-26, https://doi.org/10.1016/j.en vres.2016.06.002.

This work is available in Open Access model and licensed under a Creative Commons Attribution-NonCommercial 3.0 Poland License - http://creativecommons.org/ licenses/by-nc/3.0/pl/deed.en. 